\title{
COVID-19 Pandemic and mental health concerns: What should we expect?
}

\author{
COVID-19 Pandemisi ve psikiyatrik endişeler: Bundan sonraki süreçte ne \\ beklemeliyiz?
}

Mazlum Copur ${ }^{1}$, Sidar Copur²

1 Prof., İstanbul Arel University, School of Health Sciences Department of Child Development, Türkiye https://orcid.org/0000-0001-9218-0296

${ }^{2}$ Student, Koç University School Of Medicine, Istanbul, Türkiye https://orcid.org/0000-0003-0190-2746

\section{TO THE EDITOR}

As third recent outbreak of coronaviruses following the severe acute respiratory syndrome (SARS)$\mathrm{CoV}$ and the Middle East respiratory syndrome (MERS)-CoV, Coronavirus disease 2019 (COVID19) pandemic with now more than 2.5 million confirmed cases and 170.000 mortality originated at Chinese town Wuhan in December $2019(1,2)$. Most common presenting symptoms include cough, fatigue, fever and dyspnea while average incubation period is shown to be 4-5 days but may take up to 14 days $(3,4)$. Most common causes of mortality in infected individuals include acute respiratory distress syndrome (ARDS) and fulminant myocarditis while clinical features including acute kidney injury and acute lung injury have commonly been reported (4). Earlier reports from Wuhan demonstrated $2.8 \%$ mortality rate with median age of deceased patients of 75 , though, later reports indicate $5.6 \%$ mortality rate in China and $15.2 \%$ outside of China calculated via a model based on mean time period of 14 days between the onset of symptoms and death $(5,6)$. Despite growing number of clinical trials for pharmacological management of COVID-19 infection, no effective treatment options are yet to be identified (7). Its' higher transmission rate compared to Influenza and possible spread by asymptomatic carriers are the main factors limiting the control of disease and affecting psychosocial status of individuals along with quarantine measures (8). Psychiatric outcomes are commonly overlooked aspect of such pandemics despite being responsible from significant morbidity and work loss as observed in previous outbreaks. Incidence of psychiatric disorders assessed via Diagnostic and Statistical Manual-4 (DSM-4) at
post-SARS period is $58.9 \%$ in a study conducted with 90 SARS survivors while at least one fourth of the survivors suffered from post-traumatic stress disorder (PTSD) and $15.6 \%$ of the survivors experienced depressive symptoms $(9,10)$. Similar psychiatric outcomes have also been observed in the Swine flu outbreak of 2009 (11).

Large scale researches on psychological impacts on COVID-19 pandemic on general population are limited in number, though, with high significance. One of the initial study regarding the psychiatric consequences of COVID-19 conducted in China with 1210 participants illustrated moderate to severe depressive symptoms $(16.5 \%)$, moderate to severe anxiety symptoms $(28.8 \%)$ and moderate to severe stress levels $(8.1 \%)$ which are assessed via the Impact of Event Scale-Revised (IES-R) and the Depression, Anxiety and Stress Scale (DASS-21). Being female, having certain physical symptoms including myalgia and coryza and poor self-rated health status are shown to be statistically significant predictive factors for poorer psychiatric outcome while availability of accurate medical information and utilization of personal protective measures such as face masks appear to be protective variables (12). Another nationwide survey performed in China with 52.370 participants (64.73\% females) demonstrated that approximately $35 \%$ of the population experience psychological distress assessed via the COVID-19 Peritraumatic Distress Index (CPDI) (mean score: 23.65) while female gender, age above 60 and ages between 18 and 30, higher educational status and certain occupations are associated with higher risk (13). Higher rates of depression and anxiety have been reported in few other cross-sectional studies along with poor sleep 
quality for which anxiety and low social capita which describes low social participation and trust are potential aggravating factors $(14,15)$. Interestingly, levels of depression and anxiety in general population during the course of pandemic do not appear to change in time (16). In addition to psychological responses of general population, patients with suspected COVID-19 symptoms are more likely to develop depression and low healthrelated quality of life score according to a large scale study involving 3947 patients in which health literacy has been indicated as a protective element (17). Analysis of posts from $17.865(74.77 \%$ females, median age: 33) active Weibo users, a Chinese blogging site, revealed lower life satisfaction with elevated negative emotions including anxiety, depression and indignation (18).

In a comprehensive review study examining twentyfour studies about the psychological outcomes of quarantine restrictions, negative outcomes including PTSD, anger, depressive symptoms, emotional disturbance, irritability, insomnia, stress, fear and confusion are more commonly encountered in quarantined individuals. Furthermore, such adverse outcomes are less commonly observed in self-isolated people compared to people under obligatory quarantine restrictions. Longer duration, fear of being infected, inadequate basic life supplies, poor socioeconomic status and poor health information during quarantine period are strong predictors of worse psychological outcome. Therefore, psychological consequences of quarantine restrictions should not be underestimated and duration of quarantine should be kept as short as possible with no delay than announced dates unless in extreme cases (19).

Another crucial psychological aspect of COVID-19 pandemic that needs to be addressed is the psychosocial status of healthcare workers since more than $20 \%$ of the affected individuals in recent SARS outbreak in 2002 are healthcare workers (20). Similar to general population, studies conducted with 1257 healthcare workers $(76.7 \%$ females) in China indicate significant symptoms of depression $(50.4 \%)$, anxiety $(44.6 \%)$, insomnia $(34 \%)$ and stress $(71.5 \%)$ while females, nurses, those working in Wuhan or in close contact in patients with COVID-19 are more prone to deve- lop such symptoms (21). Additionally, physicians working in close contact with infected patients such as the ones working at infectious disease, intensive care, emergency or respiratory disease departments are two times more likely to experience anxiety and depression, 1.4 times more likely to feel fear compared to rest of the physicians and administrative staff of hospitals according to a study conducted with 2042 healthcare workers and 257 administrative employee (22). In contrast, another study including 214 participants from general population and 526 nurses (292 non-front-line and 234 front-line nurse) concluded that the vicarious traumatization scores of general population and non-front-line nurses are significantly higher than front-line nurses while no difference among nonfront-line nurses and general population have been determined (23). In addition to being a highlighted topic, social support for healthcare workers have shown to reduce the level of anxiety and increase self-efficacy in medical staff (24).

Despite increased need for psychological support and interventions by mental healthcare workers, general population is reluctant to seek professional help primarily due to quarantine and concerns regarding the higher risk of getting infected at hospital setting. To address such need, few methods have been introduced recently including telehealth and structured letter therapy (25-28). Videoconferencing, smartphone applications, email, online forums and texting are various proposed methods of telehealth (29-31). Earlier studies investigating the efficiency of telehealth in the management of depression, anxiety and post-traumatic stress disorder are promising, though, inconclusive so far $(29,32,33)$. During the early course of COVID-19 pandemic China has initiated telehealth services through multiple channels with promising outcomes on early reports (28).

As a consequence of high media coverage of the epidemic with poor medical information, lengthening of quarantine restriction period and delay in the return to regular daily activities, increasing concerns and spread arising from social media, we believe psychiatrists and psychologist should expect a surge in cases with depression, anxiety disorder, specific phobia, adjustment disorder, acute stress disorder, PTSD, insomnia and other sleep disor- 
ders and attention deficit hyperactivity disorder. Increasing the availability and usage of telehealth methods as performed in China, regulations regarding misleading information on media, establishment of guidelines regarding the psychiatric management of patients with pandemic-related issues similar to recently announced World Health Organization, transparent enlightenment of community with the latest and accurate advancement regarding COVID-19 pandemic, preparation of necessary adjustments for post-pandemic period, continuation of social relationships through digital platforms, taking self-protective measures including face-masks, providing financial supports and basic life supplies and keeping quarantine measures as short as possible without endangering any life are the possible ways to handle possible psychiatric consequences (34).

Correspondence address: Prof, Mazlum Copur, İstanbul Arel University, School of Health Sciences Department of Child Development, Türkiye scopur14@ku.edu.tr

\section{REFERENCES}

1. $\mathrm{Lu} \mathrm{H}$, Stratton $\mathrm{CW}$, Tang YW. Outbreak of pneumonia of unknown etiology in Wuhan, China: The mystery and the miracle. J Med Virol. 2020;92:401-2.

2. Li W, Yang Y, Liu ZH, Zhao YJ, Zhang Q, Zhang L, et al. Progression of Mental Health Services during the COVID-19 Outbreak in China. Int J Biol Sci. 2020;16:1732-8.

3. Huang C, Wang Y, Li X, Ren L, Zhao J, Hu Y, et al. Clinical features of patients infected with 2019 novel coronavirus in Wuhan, China. The Lancet. 2020;395:497-506.

4. Singhal T. A Review of Coronavirus Disease-2019 (COVID19). Indian J Pediatr. 2020;87(4):281-6.

5. Wang W, Tang J, Wei F. Updated understanding of the outbreak of 2019 novel coronavirus (2019-nCoV) in Wuhan, China. J Med Virol. 2020;92:441-7.

6. Baud D, Qi X, Nielsen-Saines K, Musso D, Pomar L, Favre G. Real estimates of mortality following COVID-19 infection. Lancet Infect Dis. 2020.

7. Cunningham AC, Goh HP, Koh D. Treatment of COVID-19: old tricks for new challenges. Crit Care. 2020;24:91.

8. Ferioli M, Cisternino C, Leo V, Pisani L, Palange P, Nava S. Protecting healthcare workers from SARS-CoV-2 infection: practical indications. Eur Respir Rev. 2020;29:200068.

9. Tansey CM, Louie M, Loeb M, Gold WL, Muller MP, de Jager J, et al. One-year outcomes and health care utilization in survivors of severe acute respiratory syndrome. Arch Intern Med. 2007;167:1312-20.

10. Mak IW, Chu CM, Pan PC, Yiu MG, Chan VL. Long-term psychiatric morbidities among SARS survivors. Gen Hosp Psychiatry. 2009;31:318-26.

11. Rubin GJ, Amlôt R, Page L, Wessely S. Public perceptions, anxiety, and behaviour change in relation to the swine flu outbreak: cross sectional telephone survey. Bmj. 2009;339:b2651.

12. Wang C, Pan R, Wan X, Tan Y, Xu L, Ho CS, et al. Immediate Psychological Responses and Associated Factors during the Initial Stage of the 2019 Coronavirus Disease (COVID-19) Epidemic among the General Population in China. Int J Environ Res Public Health. 2020;17:1729.

13. Qiu J, Shen B, Zhao M, Wang Z, Xie B, Xu Y. A nationwide survey of psychological distress among Chinese people in the
COVID-19 epidemic: implications and policy recommendations. Gen Psychiatr. 2020;33:e100213-e.

14. Xiao H, Zhang Y, Kong D, Li S, Yang N. Social Capital and Sleep Quality in Individuals Who Self-Isolated for 14 Days During the Coronavirus Disease 2019 (COVID-19) Outbreak in January 2020 in China. Med Sci Monit. 2020;26:e923921.

15. Wang Y, Di Y, Ye J, Wei W. Study on the public psychological states and its related factors during the outbreak of coronavirus disease 2019 (COVID-19) in some regions of China. Psychol Health Med. 2020:1-10.

16. Wang C, Pan R, Wan X, Tan Y, Xu L, McIntyre RS, et al. A longitudinal study on the mental health of general population during the COVID-19 epidemic in China. Brain Behav Immun. 2020 .

17. Nguyen HC, Nguyen MH, Do BN, Tran CQ, Nguyen TTP, Pham KM, et al. People with Suspected COVID-19 Symptoms Were More Likely Depressed and Had Lower Health-Related Quality of Life: The Potential Benefit of Health Literacy. J Clin Med. 2020;9(4).

18. Li S, Wang Y, Xue J, Zhao N, Zhu T. The Impact of COVID19 Epidemic Declaration on Psychological Consequences: A Study on Active Weibo Users. Int J Environ Res Public Health. 2020;17:2032.

19. Brooks SK, Webster RK, Smith LE, Woodland L, Wessely S, Greenberg N, et al. The psychological impact of quarantine and how to reduce it: rapid review of the evidence. Lancet. 2020;395(10227):912-20.

20. Chang D, Xu H, Rebaza A, Sharma L, Cruz CSD. Protecting health-care workers from subclinical coronavirus infection. The Lancet Respiratory Medicine. 2020;8(3):e13.

21. Lai J, Ma S, Wang Y, Cai Z, Hu J, Wei N, et al. Factors Associated With Mental Health Outcomes Among Health Care Workers Exposed to Coronavirus Disease 2019. JAMA Netw Open. 2020;3(3):e203976-e.

22. Lu W, Wang H, Lin Y, Li L. Psychological status of medical workforce during the COVID-19 pandemic: A cross-sectional study. Psychiatry Res. 2020;288:112936.

23. Li Z, Ge J, Yang M, Feng J, Qiao M, Jiang R, et al. Vicarious traumatization in the general public, members, and non-members of medical teams aiding in COVID-19 control. Brain, 
Behavior, and Immunity. 2020.

24. Xiao H, Zhang Y, Kong D, Li S, Yang N. The Effects of Social Support on Sleep Quality of Medical Staff Treating Patients with Coronavirus Disease 2019 (COVID-19) in January and February 2020 in China. Med Sci Monit. 2020;26:e923549e.

25. Zhou X, Snoswell CL, Harding LE, Bambling $\mathrm{M}$, Edirippulige S, Bai X, et al. The role of telehealth in reducing the mental health burden from COVID-19. Telemedicine and eHealth. 2020

26. Xiao C. A novel approach of consultation on 2019 novel coronavirus (COVID-19)-related psychological and mental problems: structured letter therapy. Psychiatry investigation. 2020;17:175.

27. Yao H, Chen J-H, Xu Y-F. Rethinking online mental health services in China during the COVID-19 epidemic. Asian journal of psychiatry. 2020;50:102015.

28. Liu S, Yang L, Zhang C, Xiang Y-T, Liu Z, Hu S, et al. Online mental health services in China during the COVID-19 outbreak. The Lancet Psychiatry. 2020;7(4):e17-e8.

29. Rees CS, Maclaine E. A systematic review of videoconference-delivered psychological treatment for anxiety disorders. Australian Psychologist. 2015;50(4):259-64.

30. Kauer SD, Mangan C, Sanci L. Do online mental health services improve help-seeking for young people? A systematic review. Journal of Medical Internet Research. 2014;16(3):e66.

31. Kerst A, Zielasek J, Gaebel W. Smartphone applications for depression: a systematic literature review and a survey of health care professionals' attitudes towards their use in clinical practice. European archives of psychiatry and clinical neuroscience. 2020;270(2):139-52.

32. Backhaus A, Agha Z, Maglione ML, Repp A, Ross B, Zuest $\mathrm{D}$, et al. Videoconferencing psychotherapy: A systematic review. Psychological services. 2012;9(2):111.

33. García-Lizana F, Muñoz-Mayorga I. Telemedicine for depression: a systematic review. Perspectives in Psychiatric Care. 2010;46:119-26.

34. Organisation WH. Mental health and psychosocial considerations during the COVID-19 outbreak 2020. 